\title{
The Effect of Quetiapine on Treatment of Experimental Acute Spinal Cord Injury
}

\author{
Murat Hamit AYTAR ${ }^{1}$, Soner $\mathrm{CIVI}^{2}$, Memduh $\mathrm{KAYMAZ}^{3}$, Ertan ERGUN ${ }^{4}$, Fevziye Figen $\mathrm{KAYMAZ}^{5}$, \\ Aydin PASAOGLU ${ }^{3}$
}

\author{
${ }^{1}$ Acibadem University, Vocational School of Health Services, Department of Neurosurgery, Istanbul, Turkey \\ ${ }^{2}$ Baskent University, Faculty of Medicine, Department of Neurosurgery, Adana, Turkey \\ ${ }^{3}$ Gazi University, Faculty of Medicine, Department of Neurosurgery, Ankara, Turkey \\ ${ }^{4}$ Kavaklıdere Umut Hospital, Neurosurgery Clinic, Ankara, Turkey \\ ${ }^{5}$ Hacettepe University, Faculty of Medicine, Department of Neurosurgery, Ankara, Turkey
}

\section{ABSTRACT}

AIM: It is well known that treatment modalities against secondary damage due to spinal cord injury (SCl) are very important. This phase has been researched in many experimental studies. Apoptosis is one of the major mechanisms of secondary damage on spinal cord. The present study was undertaken to determine if quetiapine, a 5-HT2 receptor blocker atypical antipsychotic agent can rescue neuronal cells from apoptosis in a SCI model.

MATERIAL and METHODS: Thirty-two female Wistar rats were separated to 4 equal groups. Total laminectomy was performed at T5-7 level and spinal cord injury was produced by using the clip compression technique. Each rat from groups "1 day" (D-I) and "7 days" (D-II) was daily injected intraperitoneally with Quetiapine $(10 \mathrm{mg} / \mathrm{kg} / \mathrm{day})$. No treatment was administered to the control groups "1 day" (K-I) and "7 days" (K-II). At the end of follow-up periods, all animals were sacrificed and spinal cords were removed. Apoptotic cells were evaluated by using immunohistochemical technique (TUNEL) in injured spinal cord specimens.

RESULTS: There was a statistically significant difference while counting ApopTag positive cells, both at 1 day groups of K-I and D-I $(p=0.00000008)$ and at 7 day groups of K-II and D-II $(p=0.000005)$. Unlike the 1-day period, a statistically significant difference was found between grey and white matter ApopTag positive cells at the $7^{\text {th }}$ day $(p=0.0001)$.

CONCLUSION: Quetiapine has a protective effect on secondary damage caused by SCI, while also can be used in post-traumatic stress disorder, depression and agitation as a versatile agent.

KEYWORDS: Spinal cord injury, Quetiapine, Apoptosis, Secondary damage

\section{INTRODUCTION}

S pinal cord injury $(\mathrm{SCl})$ is a catastrophic and common neurological disorder that has intense influences on modern life concerning physical, psychosocial, and socioeconomic perspectives. $\mathrm{SCl}$ is generally accepted to be a two-step process involving primary and secondary injury mechanisms. Acute spinal cord injury is characterized by primary axonal mechanical injury and secondary damage induced by different biochemical reactions involving also tissues surrounding the primary injured area. Pathophysiological mechanisms are essential to understand and manage spinal cord injury. Spinal cord may become damaged by the "primary mechanical injury" and damage will expand with time because of the activation of pathophysiological mechanisms called "secondary cord injury". Secondary injury of SCI may result from spinal cord edema, ischemia, free radical damage, electrolyte imbalance, 
excitotoxicity, inflammatory injury, and apoptosis (9). Various studies have investigated pharmacologic agents, such as methylprednisolone, melatonin, erythropoietin, magnesium, mexiletine, naloxone, infliximab, clotrimazole, lamotrigine and hyperbaric oxygen, that protect against or reduce the secondary injury after experimental $\mathrm{SCl}$ and among these only methylprednisolone has been shown to provide benefit in large clinical trials $(4,11,13-16,23,24,26)$.

The active ingredient quetiapine that we used in our study has a serotonin antagonist effect. Serotonin has multiple through 7 different families of receptors (5-HT1 to 5-HT7). Quetiapine is a 5-hydroxytryptamine-2 (5-HT2) receptor antagonist. 5 -HT2 receptors occupies in the cells of the blood vessel wall, myocardium, thrombocytes, mast cells and central nervous system cells widely. It is well known that serotonin also plays role in injured tissues, inflammation and inflammatory pain. Also studies of 5-HT2 receptor blockers have shown that they might be effective in the treatment of lumbar pain secondary to discopathy.

It has even been claimed that 5-HT2 blockers can provide equal pain control as non-steroid anti-inflammatory drugs (NSAIDs) (10,12).

Serotonin may also act as mediator through 5-HT2 receptors in cardiac injury due to ischemic reperfusion. In some experimental studies on the subject, it has been concluded that 5-HT2-receptor blockage prevents cellular injury due to myocardial ischemia (19). Rajesh et al. have also presented that, 5-HT2 receptor blocker sarpogrelate was preventing down regulation of anti-apoptotic protein $\mathrm{Bcl}-2$ and protecting the heart against ischemia-reperfusion injury (21).

Experimental clinical studies have also shown that a dibenzothiazepine derivative, serotonin receptor blocker atypical antipsychotic drug quetiapine was also suitable for treatment of aggression and agitation due to traumatic brain injury (17).

In the light of these data, we believed that quetiapine while also averting the neuropsychiatric complications of the trauma, could show a neuroprotective effect and decrease apoptotic cell death and negative effects secondary to injury of the spinal cord via 5-HT2 receptors.

\section{- MATERIAL and METHODS}

Thirty-two male, adult Wistar rats weighing between 250 and $300 \mathrm{~g}$ were used in this study. Four equal groups each containing 8 randomly selected rats were constituted. All the rats were obtained from the Gazi University, Experimental Animals Research Center (GUDAM) and housed in the same center. All animals were kept under controlled light in dark conditions and housed 7 days before the tests for adaptation. There was no water and food deprivation. All experiments were approved by our Institutional Review Board and performed in accordance with the local guidelines to minimize animal discomfort.

\section{Groups}

The same surgical procedures were performed on each four groups;
Group 1 (K-I): 1 day survived control group $(n=8)$

Group 2 (D-I): 1 day survived treatment group $(n=8)$

Group 3 (K-II): 7 days survived control group $(n=8)$

Group 4 (D-II): 7 days survived treatment group $(n=8)$

\section{Anesthesia and Surgical Procedure}

Anesthesia was induced by intramuscular administration of 50 $\mathrm{mg} / \mathrm{kg}$ ketamine hydrochloride (Ketalar, Pfizer; Istanbul, Turkey) and $10 \mathrm{mg} / \mathrm{kg}$ xylazine (Rompun, Bayer; Istanbul, Turkey), The rats were numbered with ear tags. Their mid-backs were shaved and cleaned with $10 \%$ polyvinylpyrrolidone/iodine. The medication groups were administered quetiapine 10 $\mathrm{mg} / \mathrm{kg} /$ day intraperitoneally 30 minutes after the trauma we caused, and then once a day at the same time for 7 days. All surgical procedures were performed under the microscope (Opmi 99, Carl Zeiss, Germany). Th5-Th7 total laminectomy was performed by the same surgeon with a standard surgical procedure to each animal $(8,20,22)$. Acute spinal injury was obtained under sterile condition with clip compression technique at level Th6 thoracic spinal cord. The spinal cord was compressed for 60 seconds by Yaşargil aneurysm clip (Figure 1). After the surgical procedure, all the animals were paraplegic.

After the surgical procedures, quetiapine was administered 10 $\mathrm{mg} / \mathrm{kg}$ intraperitoneally to animals of the D-I and D-II groups at $30^{\text {th }}$ minute of the operation. The control groups (K-I and $\mathrm{K}-\mathrm{II})$ received no treatment. First day groups (D-I and K-I) were sacrificed at $24^{\text {th }}$ hour of the trauma. Laminectomy sites were enlarged and Th6 cord trauma level resected with expanding 5 $\mathrm{mm}$ proximally and distally. The animals of groups of $\mathrm{K}-\mathrm{II}$ and D-II were followed up for 7 days. Quetiapine was administered daily to each rat $(10 \mathrm{mg} / \mathrm{kg}$ IP). After 7 days, all animals of group K-II and D-II were sacrificed and their injured cords were resected with the same procedure.

\section{Immunohistochemical Procedure}

All the spinal cord samples were fixed with formalin and embedded in paraffin blocks. Sections with $5 \mu \mathrm{m}$ thickness were obtained from paraffin blocks on special sialinized slides. Following deparaffinization, some samples were stained with haematoxylin-eosin and the accuracy of the field was checked. Other sections were marked with the immunohistochemical TUNEL method by using the ApopTag Plus Peroxidase In Situ Apoptosis Detection Kit (Chemicon, USA cat\#S7101). Background staining was achieved by methyl green. After dehydration with $100 \%$ n-butanol, all slides were closed using closure balsam.

\section{Sample Evaluation}

All the immunohistochemically stained samples were analyzed by light microscopy (Leica Microsystems RM6000, Germany). The cells with brown nuclear staining, over the methylgreenstained light green background were considered ApopTag positive. On each slide, four randomly selected areas (two from gray matter, two from white matter) were evaluated under x40 magnification. ApopTag positive cells were counted by using ocular grid and noted for each group separately. The apoptotic cells of the groups were shown in Figure $2 A, B$ and Figure $3 \mathrm{~A}, \mathrm{~B}$. 


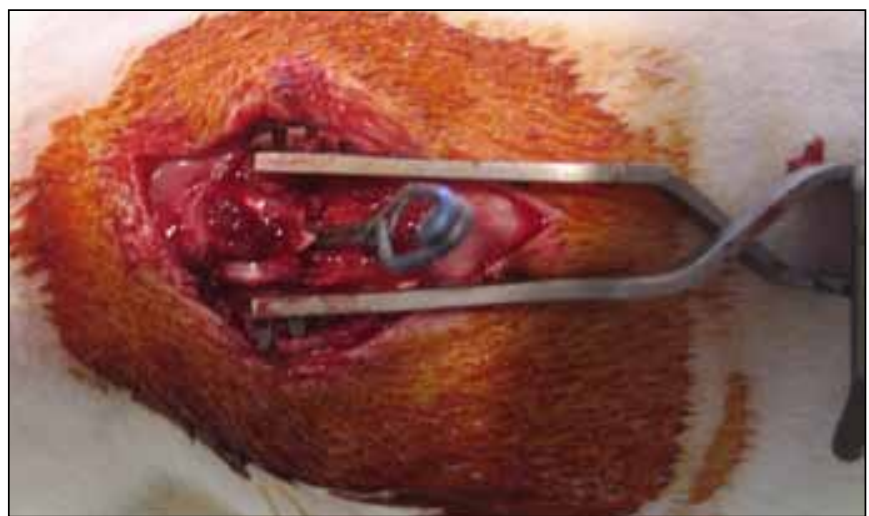

Figure 1: The photo of the clip compression technique by Yasargil aneurysm clip at level Th6 thoracic spinal cord.

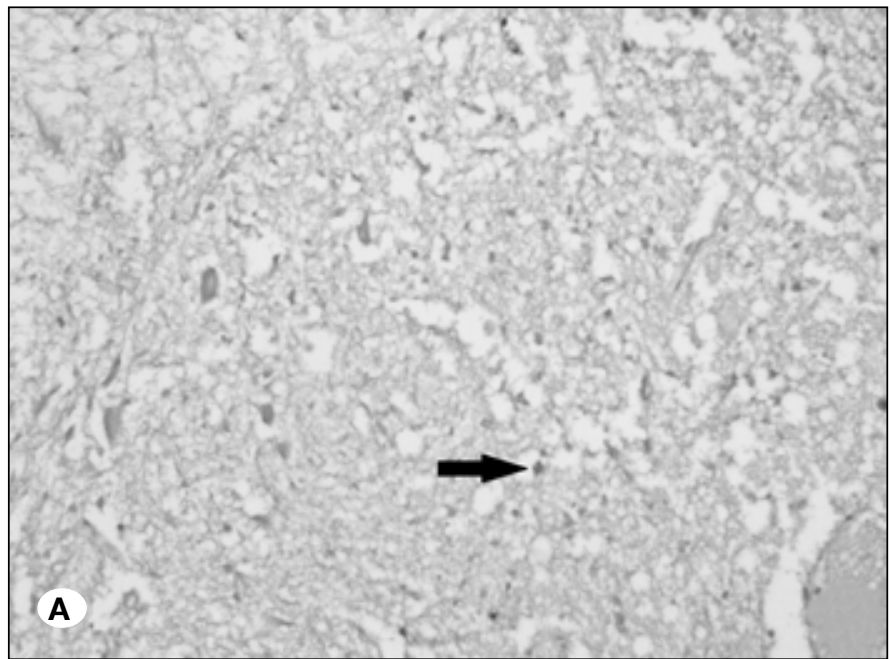

Additionally, all the samples stained with haematoxylin-eosin in each group were evaluated under the light microscope with x50 and x100 magnification to examine the tissue integrity and characteristics (Figure 4).

\section{Statistical Method}

Differences between groups regarding cells were analyzed using two-way analysis of variance. $\mathrm{P}$ value $<0.05$ was considered as statistically significant.

\section{RESULTS}

ApopTag positive cells of grey and white matter were counted one by one and evaluated with immunohistochemical staining. Statistical analysis results are shown in Table I. On day 1

Figure 2: A) In the control group (K-I), apoptag positive cells can be seen in brown color during the first day as a result of tissue integrity impairment. Black arrow indicates apoptotic cell sample (original magnification 20x). B) Less apoptag positive cells can be seen in the first day of the experimental group (D-I) compared to the control group. Black arrow indicates apoptotic cell sample (original magnification 20x).
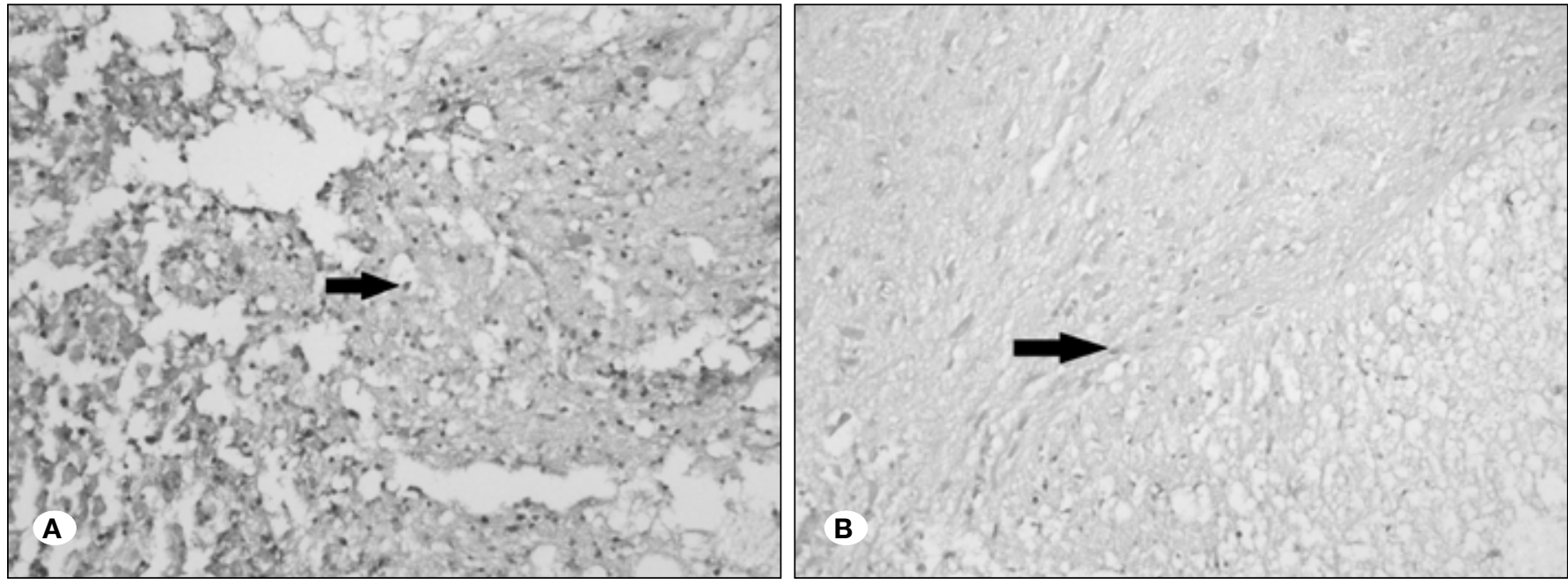

Figure 3: A) Many apoptag positive, brown colored cells can be seen on the tissue impaired cord on the $7^{\text {th }}$ day of the control group (KII). Black arrow indicates apoptotic cell sample (original magnification 20x). B) The lower number of positive apoptag cells in the $7^{\text {th }}$ day research group (D-II) compared to the control group was noticeable. Black arrow indicates apoptotic cell sample (original magnification 20x). 
there was a statistically significant $(p=0.00000008)$ difference between the control group and the study group concerning ApopTag positive cells but no significant difference was found between grey matter and white matter ApopTag positive cells $(p=0.216)$. On day 7 there was also a statistically significant difference concerning ApopTag positive cells of the control group and the study group ( $p=0.000005)$, and unlike the acute period statistically significant difference was found between grey and white matter ApopTag positive cells $(p=0.0001)$. Figure 5 shows the comparison of average apoptotic cell numbers at the first and seventh days of the control group and the research group in the grey matter, white matter and all areas.

Apoptotic cell counts were also evaluated one by one for the grey matter, and for the white matter separately. Cellular and group (control-study group) interaction in the acute period between control (K-I) and study (D-I) groups were statistically

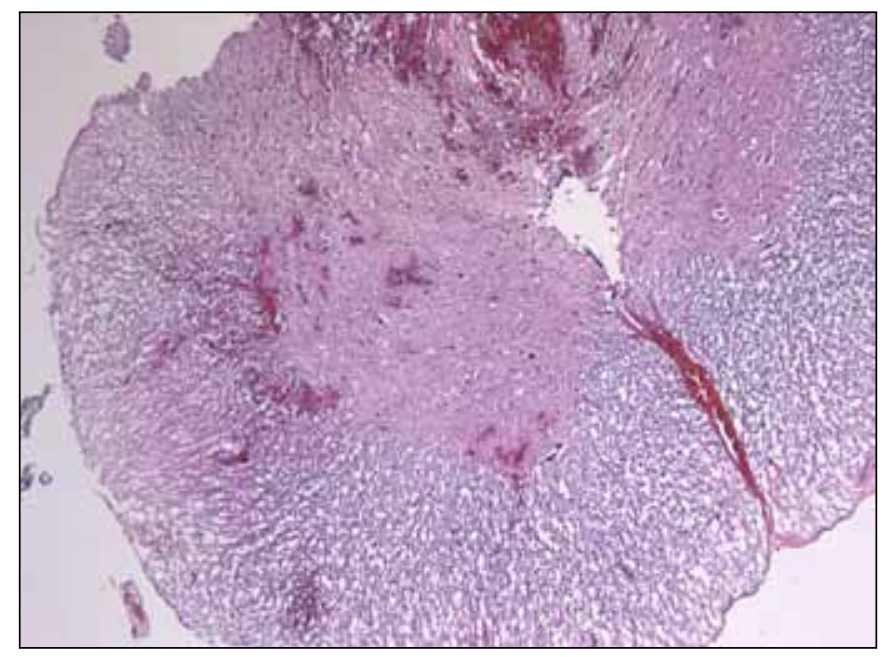

Figure 4: After the experimental injury, spinal cord section stained with haematoxylin-eosin shows traumatic injury and bleeding areas under the light microscope with $\times 50$ magnification. insignificant $(\mathrm{p}=0.889)$ but (K-II and $\mathrm{D}-\mathrm{II})$ cellular and group (control-study group) interaction in the subacute period were found to be statistically significant $(\mathrm{p}=0.002)$.

It was observed that quetiapine provided better protection on grey matter cells than white matter cells in the subacute period. This condition was also observed on immunohistochemical staining as presence of more apoptotic cells in the white matter compared to the grey matter.

\section{DISCUSSION}

Spinal cord injury can be seen at any age, and it is an important medical and social problem. The victims are usually at the second or third decades of their lives (9). Many studies have focused on the secondary injury mechanism of SCl. It has been suggested that after $\mathrm{SCl}$, apoptosis is a crucial cause of cell loss that contributes to neurological deficit $(2,7,18)$.

Many studies have reported an important morphological and biochemical evidence of the presence of apoptosis after $\mathrm{SCl}$. Apoptosis occurs in many neurons, oligodendrocytes, microglia and astrocytes. Many weeks after the injury the death of oligodendrocytes in white matter tracts continues, and this may contribute to post-injury demyelination (3). After the role of apoptosis and leading pathways were discovered in secondary injury, many useful agents blocking these pathways were experimentally used. Yune et al. used 17-beta estradiol and experimentally showed its efficacy. In another study, the preventive effect of erythropoietin from apoptosis caused by post-traumatic spinal cord injury has been shown $(1,25)$. Luo and Shi, in a recent experimental study, showed that polyethylene glycol inhibited apoptotic cell death after spinal trauma. It has been previously known that polyethylene glycol shows neuroprotective effects by stabilizing the cellular and mitochondrial membranes and in this study it was found that it inhibits cytochrome c, thus blocking apoptosis (18). A different study showed that sarpogrelate a 5-HT2 receptor blocker, blocked cardiomyocytes from dying through apoptotic ways and prevents postischemic myocardial dysfunction $(19,21)$.

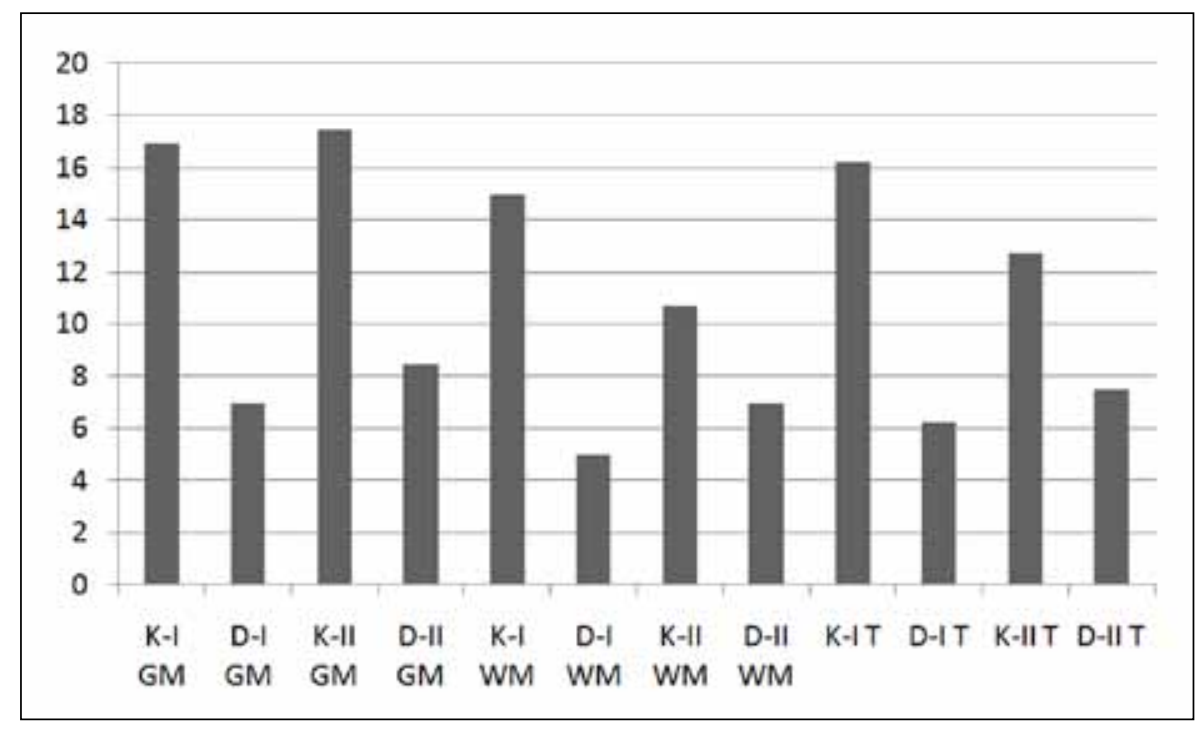

Figure 5: Graphic representation of the average apoptotic cell number of each group in white matter areas, grey matter areas and all areas (GM: Grey Matter, WM: White Matter, T: Total). 
Aytar MH. et al: The Effect of Quetiapine in Acute SCI

Table I: The Number of Apoptotic Cells in 4 Randomly Selected Fields from the Grey and White Matters of Each Animal in the Group

\begin{tabular}{llrrrrrr}
\hline & $\mathbf{n}$ & Mean & Std. Deviation & Median & Minimum & Maximum \\
\hline \multirow{3}{*}{ K-I } & Grey matter & 8 & 17.18 & 2.13 & 17.00 & 13.5 & 20.0 \\
\cline { 2 - 8 } & White matter & 8 & 15.62 & 3.55 & 15.00 & 12.0 & 23.5 \\
\cline { 2 - 8 } & Total & 16 & 16.40 & 2.94 & 16.25 & 12.0 & 23.5 \\
\hline \multirow{3}{*}{ D-I } & Grey matter & 8 & 7.00 & 2.93 & 7.00 & 3.5 & 12.0 \\
\hline & White matter & 8 & 5.75 & 3.70 & 5.00 & 1.5 & 11.5 \\
\cline { 2 - 8 } & Total & 16 & 6.37 & 3.29 & 6.25 & 1.5 & 12.0 \\
\hline \multirow{3}{*}{ K-II } & Grey matter & 8 & 17.68 & 4.30 & 17.5 & 12 & 26.5 \\
\cline { 2 - 8 } & White matter & 8 & 10.43 & 1.98 & 10.75 & 6.5 & 13.5 \\
\cline { 2 - 8 } & Total & 16 & 14.06 & 4.94 & 12.75 & 6.5 & 26.5 \\
\hline \multirow{2}{*}{ D-II } & Grey matter & 8 & 7.68 & 2.03 & 8.50 & 3.5 & 9.5 \\
\hline & White matter & 8 & 6.81 & 1.06 & 7.00 & 5.0 & 8.0 \\
\cline { 2 - 8 } & Total & 16 & 7.25 & 1.63 & 7.5 & 3.5 & 9.5 \\
\hline
\end{tabular}

The 5-HT2-receptor group that is our subject was shown to be related to apoptotic cellular death mechanisms secondary to cranial or spinal ischemia or trauma. Capela et al. have used 3,4-Methylenedioxymethamphetamine (Extacy-MDMA) in their studies in 2006 and 2007 (5,6). It was shown that MDMA had serotonergic effects, especially causing apoptosis through 5-HT2 receptor pathway. Apoptosis can be prevented by using ketanserin, which is a 5-HT2 blocking agent $(6,21)$.

Quetiapine is well-known in psychiatry. Besides its wide use in agitation and control of aggression, according to this study it finds a wide use in the post-traumatic brain injury period. It is also used in the treatment of post-traumatic stress disorders. Neurosurgical patients exposed to post-traumatic spinal injury will therefore be able to benefit from the versatile therapeutic use as an auxiliary agent.

Apoptotic pathways constitute a very important mechanism of secondary injury. Our study has shown that quetiapine had a protective effect on apoptotic deaths in cells of secondary injury in our experimental spinal cord injury model created by the clip compression technique. Its effect was related to the blockage of 5-HT2 receptors, so finally quetiapine seems to have an important protective mechanism. Therefore, quetiapine can be considered in post-traumatic stress disorders, agitation, aggressiveness, and the treatment of depression in patients with $\mathrm{SCl}$ and could be a versatile option to treat the damaged cord.

\section{CONCLUSION}

Quetiapine has a protective effect on secondary damage caused by spinal cord injury, and can also be used in posttraumatic stress disorder, depression and agitation as a versatile agent. However, its routine use in clinical practice has to be supported by further studies. We believe that studies performed at molecular levels elucidating the effect on neurons and glial cells would be appropriate.

\section{REFERENCES}

1. Arishima Y, Setoguchi T, Yamaura I, Yone K, Komiya S: Preventive effect of erythropoietin on spinal cord cell apoptosis following acute traumatic injury in rats. Spine 31 : 2432-2438, 2006

2. Beattie MS, Farooqui A, Bresnahan JC: Review of current evidence for apoptosis after spinal cord injury. J Neurotrauma 17:915-925,2000

3. Beattie MS, Hermann GE, Rogers RC, Bresnahan JC: Cell death in models of spinal cord injury. Prog Brain Res 137: 3747,2002

4. Bracken MB: Steroids for acute spinal cord injury. Cochrane Database Syst Rev 3:CD001046, 2002

5. Capela JP, Fernandes E, Remiao F, Bastos ML, Meisel A, Carvalho F: Ecstasy induces apoptosis via 5-HT(2A)-receptor stimulation in cortical neurons. Neurotoxicology 28: 868-875, 2007

6. Capela JP, Ruscher K, Lautenschlager M, Freyer D, Dirnagl $\mathrm{U}$, Gaio AR, Bastos ML, Meisel A, Carvalho F: Ecstasyinduced cell death in cortical neuronal cultures is serotonin 2A-receptor-dependent and potentiated under hyperthermia. Neuroscience 139: 1069-1081, 2006

7. Eldadah BA, Faden Al: Caspase pathways, neuronal apoptosis, and CNS injury. J Neurotrauma 17:811-829, 2000

8. Ellenbroek BA, Lubbers LJ, Cools AR: Activity of "seroquel" (ICl 204,636) in animal models for atypical properties of antipsychotics: A comparison with clozapine. Neuropsychopharmacology 15: 406-416,1996 
9. Emmez H, Borcek AO, Kaymaz M, Kaymaz F, Durdag E, Civi S, Gulbahar O, Aykol S, Pasaoglu A: Neuroprotective effects of gabapentin in experimental spinal cord injury. World Neurosurg 73:729-734, 2010

10. Hashizume $H$, Kawakami M, Yoshida M, Okada M, Enyo $Y$, Inomata Y: Sarpogrelate hydrochloride, a 5-HT2A receptor antagonist, attenuates neurogenic pain induced by nucleus pulposus in rats. Spine 32: 315-320, 2007

11. Ildan F, Polat S, Oner A, Isbir T, Gocer Al, Tap O, Kaya M, Karadayi A: Effects of naloxone on sodium and potassiumactivated and magnesium-dependent adenosine-5'triphosphatase activity and lipid peroxidation and early ultrastructural findings after experimental spinal cord injury. Neurosurgery 36: 797-805, 1995

12. Kanayama M, Hashimoto T, Shigenobu K, Oha F, Yamane $S$ : New treatment of lumbar disc herniation involving 5-hydroxytryptamine2A receptor inhibitor: A randomized controlled trial. J Neurosurg Spine 2: 441-446,2005

13. Kaptanoglu E, Beskonakli E, Solaroglu I, Kilinc A, Taskin Y: Magnesium sulfate treatment in experimental spinal cord injury: Emphasis on vascular changes and early clinical results. Neurosurg Rev 26: 283-287, 2003

14. Kaptanoglu E, Caner HH, Surucu HS, Akbiyik F: Effect of mexiletine on lipid peroxidation and early ultrastructural findings in experimental spinal cord injury. J Neurosurg 91: 200-204, 1999

15. Kaptanoglu E, Solaroglu I, Okutan O, Surucu HS, Akbiyik F, Beskonakli E: Erythropoietin exerts neuroprotection after acute spinal cord injury in rats: Effect on lipid peroxidation and early ultrastructural findings. Neurosurg Rev 27:113-120, 2004

16. Kaptanoglu E, Tuncel M, Palaoglu S, Konan A, Demirpence $\mathrm{E}$, Kilinc K: Comparison of the effectsof melatonin and methylprednisolone in experimental spinal cord injury. J Neurosurg 93: 77-84, 2000

17. Kim E, Bijlani B: A pilot study of Quetiapine treatment of aggression due to traumatic brain injury. J Neuropsychiatry Clin Neurosci 18(4):547-549,2006
18. Luo J, Shi R: Polyethylene glycol inhibits apoptotic cell death following traumatic spinal cord injury. Brain Res 1155: 10-16, 2007

19. Muto T, Hotta Y, Miyazeki K, Hiroaki A, Ishikawa N, Hasegawa T, Sugimoto $Y$, Yamada J, Miki Y: Protective effects of sarpogrelate, a 5-HT2A antagonist, against postischemic myocardial dysfunction in guinea-pig hearts. Mol Cell Biochem 272: 119-132, 2005

20. Orsetti M, Canonigo PL, Dellarole A, Colella L, DiBrisco F, Ghi $\mathrm{P}$ : Quetiapine prevents anhedonia induced by acute or chronic stres. Neuropsychopharmacology 32:1783-1790, 2007

21. Rajesh KG, Suzuki R, Maeda H, Murio Y, Sasaguri S: 5-HT2 receptor blocker sarpogrelate prevents downregulation of antiapoptotic protein $\mathrm{Bcl}-2$ and protects the heart against ischemia-reperfusion injury. Life Sci 79:1749-1755, 2006

22. Robertson GS, Matsumura H, Fibiger HC: Induction patterns of Fos-Like immunoreactivity in the forebrain as predictors of atypical antipsychotic activity. J Pharmacol Exp Ther 271: 1058-1066, 1994

23. Tufan K, Oztanir N, Ofluoglu E, Ozogul C, Uzum N, Dursun A, Pasaoglu $H$, Pasaoglu A: Ultrastructure protection and attenuation of lipid peroxidation after blockade of presynaptic release of glutamate by lamotrigine in experimental spinal cord injury. Neurosurg Focus 25:6, 2008.

24. Usul H, Arslan E, Cansever T, Cobanoglu U, Baykal S: Effects of clotrimazole on experimental spinal cord ischemia/ reperfusion injury in rats. Spine 33: 2863-2867, 2008

25. Vitellaro-Zuccarello L, Mazzetti S, Madaschi L, Bosisio P, Gorio A, De Biasi S: Erythropoietin-mediated preservation of the white matter in rat spinal cord injury. Neuroscience 144:865-877, 2007

26. Yu Y, Matsuyama Y, Yanase M, Ito S, Adachi K, Satake K, Ishiguro N, Kiuchi K: Effects of hyperbaric oxygen on GDNF expression and apoptosis in spinal cord injury. Neuroreport 15: 2369-2373, 2004 